\title{
Achalasia and diffuse oesophageal spasm in siblings
}

\author{
M. D. KAYE ${ }^{1}$ AND J. E. DEMEULES
}

From the Departments of Medicine and Surgery, University of Vermont College of Medicine, Burlington, Vermont, USA

SUMMARY We report the occurrence of achalasia and diffuse oesophageal spasm in brother and sister. The familial occurrence of these unusual disorders is consistent with the possibility that they share a common aetiology and indicates the potential importance of genetic predisposition.

Achalasia is uncommon, and florid diffuse oesophageal spasm rare. The relationship between these two disorders is controversial. Their occurrence in siblings has not, to our knowledge, been described before.

\section{Case reports}

CASE 1

A. G., a white woman born in 1933 , first developed high epigastric pain in 1965 during a pregnancy which was complicated by hyperemesis and frequent heartburn. After delivery, her heartburn disappeared but episodic high epigastric pain, sharp in nature, usually precipitated by eating and with radiation to lower substernum and back, persisted. Pain was especially troublesome after cold or carbonated beverages, and was associated with lower substernal dysphagia, described as a sensation of 'blockage' which forced her to stop eating. She also noted posturally-related sour regurgitation. Her symptoms were first evaluated in 1972 when physical examination was negative. Barium swallow (Fig. 1) showed an axial hiatal hernia and disordered motility below the aortic arch with prominent tertiary waves and early diverticulum formation. Oesophagoscopy confirmed the presence of tertiary waves and axial hernia and revealed normal oesophageal mucosa with a sharply defined gastro-oesophageal junction. A biopsy taken from the distal oesophagus was normal. At subsequent oesophagoscopy with Rubin tube biopsy of the distal oesophagus in January 1978, the findings were similar. Oesophageal

${ }^{1}$ Address for correspondence and reprint requests: Dr. Michael D. Kaye, Department of Medicine, Given Building, University of Vermont, Burlington, Vermont 05401, USA.

Received for publication 29 March 1979

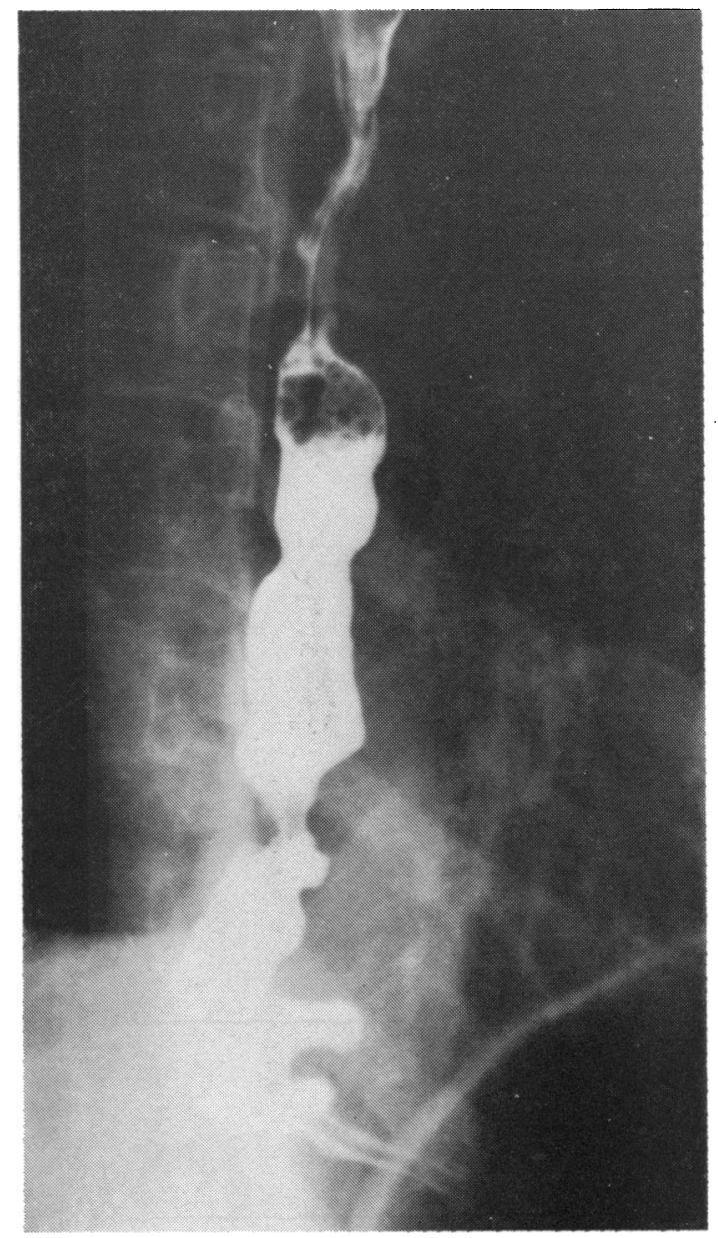

Fig. 1 Case 1. (A. G.) Barium swallow, March 1972. Incoordinate contraction with early diverticulum formation. 
manometry (Fig. 2) was performed in January 1978 using a triple-lumen tube perfused by a pneumohydraulic capillary infusion system (Arndorfer Medical Specialties Co., Greenfield, Wisc., USA) and connected by Bell and Howell transducers to a Gilson Macropolygraph Multi-channel Recorder Mean maximum end-expiratory pressure in the lower oesophageal sphincter was $1.73 \mathrm{kPa}(13 \mathrm{~mm} \mathrm{Hg})$. Relaxation of the sphincter in response to swallowing was frequently incomplete or abnormally brief. In the distal oesophageal body, spontaneous simultaneous contractions occurred frequently, and contractions in response to swallowing were prolonged and repetitive. The majority of postdeglutitive contractions in the distal half of the oesophageal body were simultaneous and abnormally powerful, with amplitudes generally exceeding $20 \mathrm{kPa}(150 \mathrm{~mm} \mathrm{Hg})$ and sometimes exceeding $47 \mathrm{kPa}$ $(350 \mathrm{~mm} \mathrm{Hg})$. Normal peristaltic progression of contractions occurred regularly in the proximal oesophagus.

The patient's symptoms did not respond to trials of antacids, sublingual nitroglycerin, anticholingergic agents, and diazepam. They became increasingly incapacitating, and in March 1978 she underwent an oesophageal myotomy which extended from $2 \mathrm{~cm}$ above the aortic arch to the anterior gastric wall. Myotomy was combined with a Collis gastroplasty and Nissen fundoplication. At surgery, the oesophageal muscle was thickened to approximately $8 \mathrm{~mm}$.

Postoperatively, her dysphagia and pain were markedly improved, though intermittent sour regurgitation persisted. Barium swallow showed some dilatation of the distal two-thirds of the oesophageal body with poor emptying in the recumbent position. Oesophageal manometry showed a very marked reduction of contraction amplitudes in the affected portion of the oesophageal body.

\section{CASE 2}

B. M., a white male hospital technician and brother of A. G., presented at the age of 35 years in September 1972 with a one-year history of gradually worsening dysphagia for both solids and liquids, associated with frequent regurgitation of undigested material. He denied heartburn, chest pain, sour regurgitation, or weight loss. Physical examination was unremarkable apart from mild obesity and

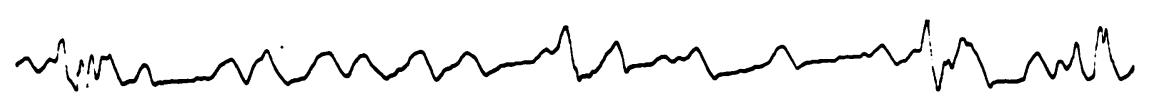

$[200 \mathrm{~mm}$ Ho
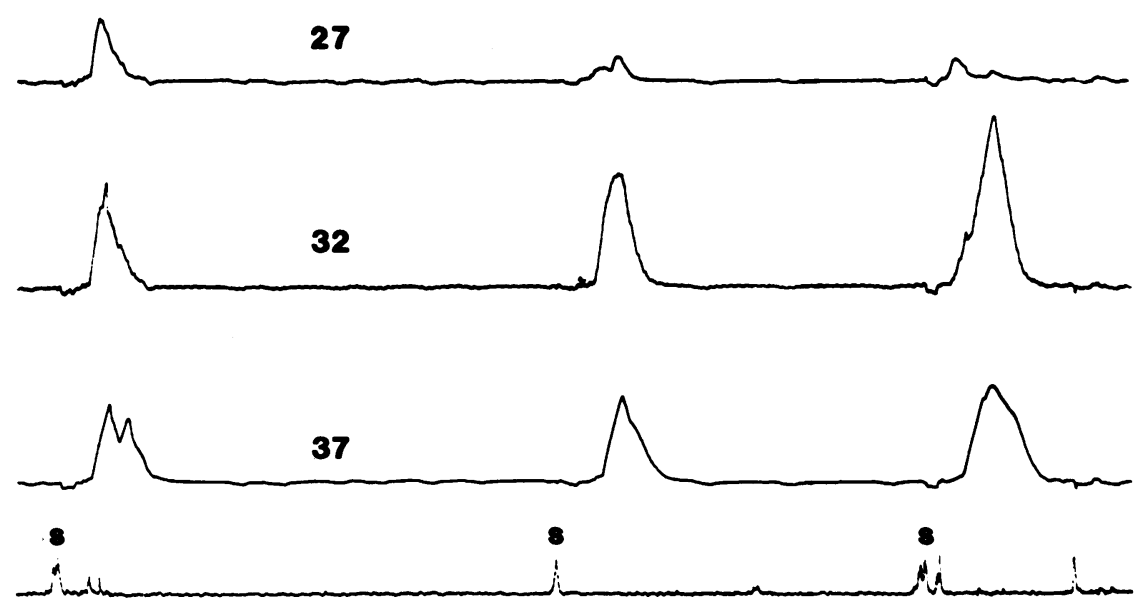

Fig. 2 Case 1.

(A. G.) Oesophageal manometry, January 1978. Upper tracing is a pneumograph (inspiration downwards). Middle three tracings are from asophageal body, with numbers indicating distance in centimetres of each opening from the incisors. Lower tracing is an electro-myograph (' $s$ ' represents swallow). Note that contractions are powerful, somewhat prolonged, and simultaneous at lower two recording points. The pressure scale $(200 \mathrm{~mm} \mathrm{Hg})$ is equivalent to $26.6 \mathrm{kPa}$. 
widespread psoriatic lesions affecting skin and nails. Barium swallow then and subsequently (Fig. 3) showed early oesophageal dilatation, feeble incoordinate contractions, poor emptying, and a distal oesophageal tapering ('bird beak') with a small axial hiatal hernia. Oesophagogastroduodenoscopy confirmed the radiographic findings of dilatation and tertiary waves. The gastro-oesophageal junction appeared normal but presented some resistance to passage of the endoscope (Olympus GIFD). Stomach and duodenum were unremarkable. Pneumatic dilatation (Mosher bag) under fluoroscopic control produced amelioration of symptoms for some months. His symptoms then recurred and did not improve after a second pneumatic dilatation in November 1973. He underwent a Heller's myotomy with Nissen fundoplication in December 1973. Since surgery he has had minimal dysphagia and has not developed symptoms of gastrooesophageal reflux. Oesophageal manometry in April 1978, approximately $3 \frac{1}{2}$ years after surgery, showed a poorly defined lower oesophageal sphincter, feeble non-propulsive contractions in the lower half of the oesophageal body, and normal peristalsis in the upper oesophagus. (Fig. 4).

\section{FAMILY HISTORY}

The paternal grandfather of A. G. and B. M. was frequently observed, while eating, to have "choking spells' during which he thumped his chest with his fists and appeared very uncomfortable. He never sought medical attention for this problem.

\section{Discussion}

In patient A. G., the symptom complex, radiographic appearances, and manometric findings were typical of diffuse oesophageal spasm. Despite her symptom of sour regurgitation, it is very unlikely that her spasm was secondary to oesophageal inflammation in response to gastro-oesophageal reflux, as her oesophageal mucosa was normal, both visually and histologically, on two separate occasions six years apart.

The diagnosis of achalasia was established in patient B. M. on the basis of consistent symptoms, characteristic radiographic findings, an absence of other causes of oesophageal dilatation, and excellent response to a Heller's myotomy. At oesophageal manometry performed $3 \frac{1}{2}$ years after surgery, the contraction pattern in the lower oesophagus was typical of that seen in achalasia. The peristaltic contractions observed in the upper oesophagus are not characteristic of untreated achalasia, but return of peristalsis after myotomy for achalasia has been described (Mellow, 1976).

Although the clinical, radiographic, and manometric features of classical forms of achalasia and diffuse oesophageal spasm are different, there is some evidence to suggest that these disorders may be aetiologically related. Thus, transition from diffuse oesophageal spasm to achalasia has been described (Kramer et al., 1967b); an intermediate syndrome, 'vigorous achalasia' (Sanderson et al., 1967), with features common to both disorders is seen not

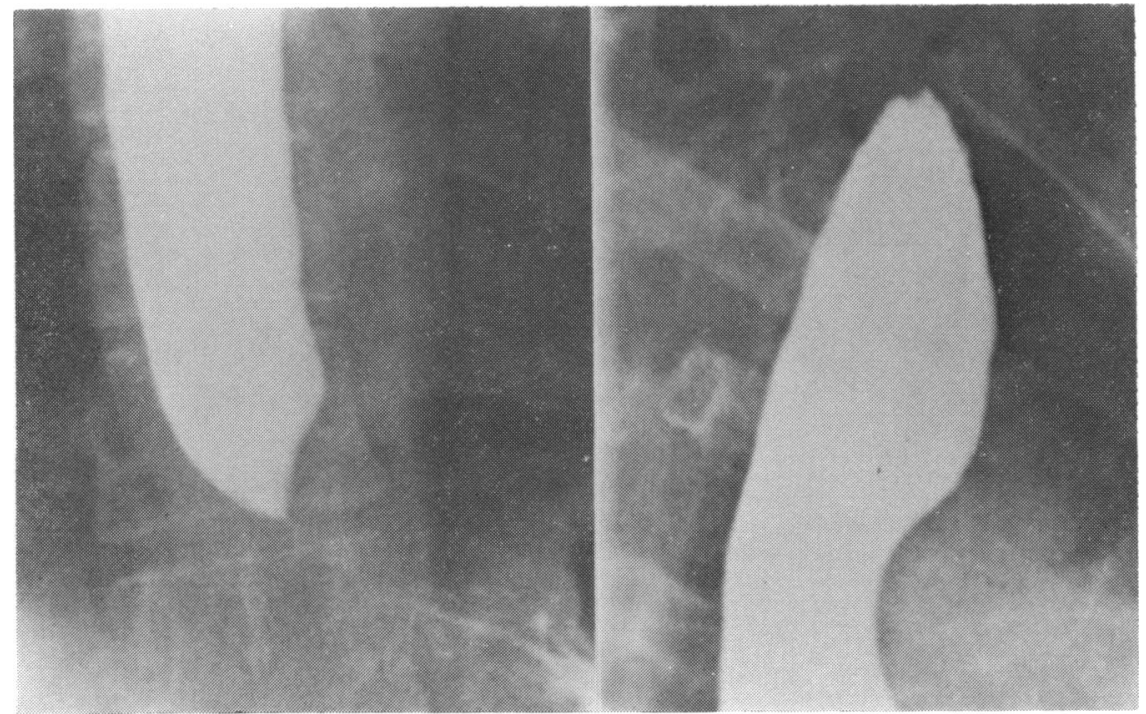

Fig. 3 Case 2. (B. M.) Barium swallow, May 1972, with views of proximal (right) and distal (left) resophagus. Note asophageal dilatation, with distal tapering 'bird-beak' appearance. 


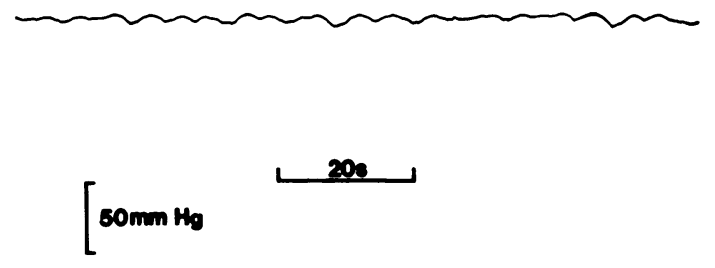

infrequently; sensitivity to cholinergic agents such as methacholine occurs in both disorders (Kramer and Ingelfinger, 1951; Kramer et al., 1967a); and vagotomy in the monkey may induce a syndrome resembling either achalasia or diffuse oesophageal spasm (Binder et al., 1968). The occurrence of achalasia and diffuse oesophageal spasm in siblings provides additional indirect evidence that the two disorders may share a common aetiology. In addi-

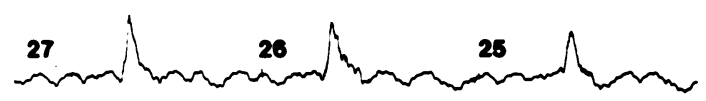
tion, it underlines the possible importance of genetic predisposition.

\section{References}
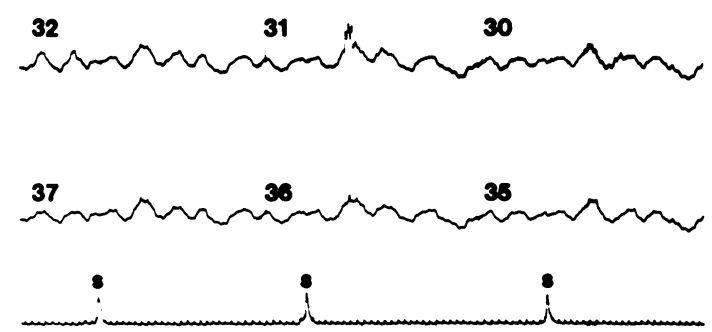

Fig. 4 Case 2. (B. M.) Oesophageal manometry. Notations are as in Fig. 2. Note that contractions distally are feeble, repetitive, and simultaneous. In the proximal lead contractions are of more normal amplitude. There is peristaltic progression between the proximal and middle recording points. The pressure scale $(50 \mathrm{~mm}$ $\mathrm{Hg}=6.65 \mathrm{kPa}$ ) is different from that in Fig. 2.

Binder, H. J., Bloom, D. L., Stern, H., Solitare, G. B., Thayer, W. R., and Spiro, H. M. (1968). The effect of cervical vagectomy on esophageal function in the monkey. Surgery, 64, 1075-1083.

Kramer, P., Fleshler, B., McNally, E., and Harris, L. D. (1967a). Oesophageal sensitivity to mecholyl in symptomatic diffuse spasm. Gut, 8, 120-127.

Kramer, P., Harris, L. D., and Donaldson, R. M., Jr. (1967b). Transition from symptomatic diffuse spasm to cardiospasm. Gut, 8, 115-119.

Kramer, P., and Ingelfinger, F. J. (1951). Esophageal sensitivity to mecholyl in cardiospasm. Gastroentereology, 19, 242-253.

Mellow, M. H. (1976). Return of esophageal peristalsis in idiopathic achalasia. Gastroenterology, 70, 1148-1151.

Sanderson, D. R., Ellis, F. H., Jr., Schlegel, J. F., and Olsen, A. M. (1967). Syndrome of vigorous achalasia: clinical and physiologic observations. Diseases of the Chest, 52, 508-517. 